\title{
Simulation of Localized Surface Plasmon Resonance of Silver Nanoparticles with Graphene Coating Utilizing Maxwell-Garnett Theory
}

\author{
Kavita, R.K. Verma*
}

Department of Physics, Central University of Rajasthan, NH-8 Bandarsindri, Ajmer 305817, Rajasthan, India

(Received 11 January 2021; revised manuscript received 24 March 2021; published online 09 April 2021)

\begin{abstract}
Surface plasmon resonance (SPR) is an important technique for various optical fiber sensors, biomedical applications, imaging and numerous optical devices. Surface plasmons are the transverse magnetically polarized surface waves generated due to the excitation of surface electrons at the interface of metal and dielectric. The excitation of surface plasmons in metal nanoparticles exhibits a strong absorption band for UV-Visible region which is not present in the spectrum of bulk metal layer. These are called localized surface plasmons (LSPs). LSPs are the collective oscillations of free electron cloud in metal nanoparticles which result in a strong absorption band. When the wavelength of incident light becomes resonant to the wavelength of oscillating free electrons, the phenomenon is termed as localized surface plasmon resonance (LSPR). In the present theoretical work, we have performed simulations using MATLAB to get the extinction (which gives the value of absorption coefficient) cross-section variation with the incident light wavelength for graphene coated silver nanoparticles. In order to get the effective dielectric constant of the proposed structure, analytically, the Maxwell-Garnett (MG) theory has been used.
\end{abstract}

Keywords: SPR, LSPR, Nanoparticle, Sensor, Graphene.

\section{INTRODUCTION}

From the past few decades, to approach more precise and instant detection in many physical, chemical and biomedical applications, the technique of surface plasmon resonance (SPR) has been widely used [1]. In this technique, the conduction electrons interact with the incident light containing electric and magnetic field to generate the surface plasmon wave. When the p-polarized light is incident on the metal-dielectric interface, an absorption band occurs corresponding to a wavelength which is in resonance with the oscillating electrons at the metal dielectric interface. This phenomenon is termed as Surface Plasmon Resonance and the corresponding wavelength is called as resonance wavelength. In Localized Surface Plasmon Resonance (LSPR), the bulk metal is replaced with the nanoparticles in order to increase the absorption of light [2]. Gold and silver are the most preferably used metal nanoparticles because of their peculiar optical properties. When light is incident on the metaldielectric interface, some part of light gets absorbed and rest of the light get scattered. Extinction coefficient is the combination of the absorption coefficient and the scattering coefficient. In order to interplay with the extinction coefficient, several modifications can be done such as changing the shape and size of the nanoparticles. Resonance wavelength and extinction coefficients are highly dependent on shape, size and environment of the metal nanoparticles [3]. For the preparation of nanoparticles of different shapes and sizes, solvothermal and hydrothermal techniques can be used as given in the literature $[4,5]$. In the present study we have theoretically simulated the extinction coefficient for metal nanoparticles coated on to the core of the optical fiber. To extend the study further these metal nanoparticles are further assumed to be coated by a layer of graphene. The effect of metal nanoparticle size and their shape on the resonance wavelength and the extinction/absorption coefficient have also been studied. The Maxwell-Garnett theory has been used to derive analytically the effective dielectric constant of the proposed structure.

\section{THEORY}

\subsection{Variation of Electric and Magnetic Field}

In order to see the variation of electric and magnetic field at the interface of the metal and dielectric we have plotted the same at a metal dielectric interface. The variation of electric and magnetic field along the interface is shown in Fig. 1a and Fig. 1b, respectively. For these simulations the interface of silver and glass medium has been used. This interface is in $x-y$ plane. The direction of propagation is along $x$ whereas the distribution of refractive index takes place along $z$-axis.

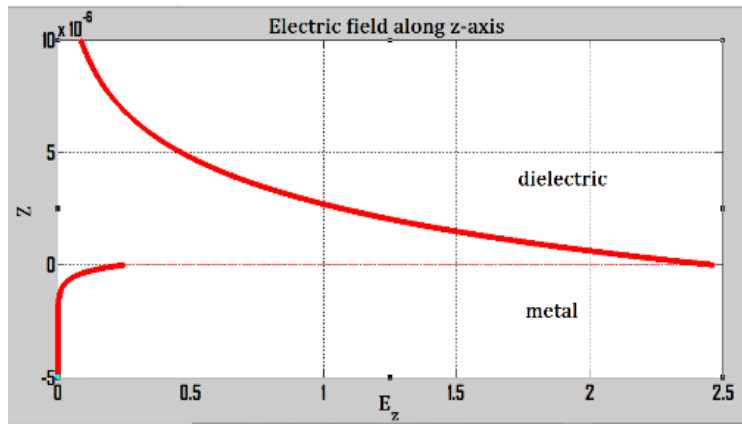

Fig. 1a - Electric field variation along the $z$-axis

\footnotetext{
*rkverma@curaj.ac.in

The results were presented at the International Conference on Multifunctional Nanomaterials (ICMN2020)
} 


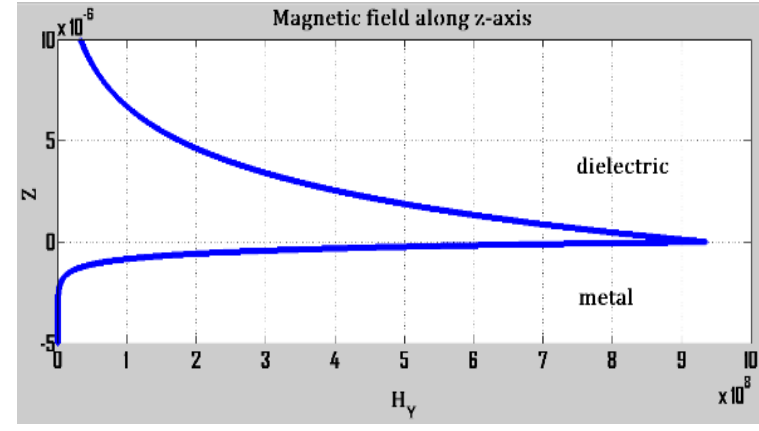

Fig. 1b-Magnetic field variation along the $z$-axis

Fig. 1a, b show the variation of electric and magnetic field along the $z$-axis. It can be inferred from these curves that electric field is discontinuous at the metal - dielectric interface whereas magnetic field is continuous at the interface.

\subsection{Extinction Coefficient and Resonance Wave- length Dependence on Shape, Size and Environment of the Nanoparticles}

Extinction coefficient is the combination of the scattering coefficient and the absorption coefficient given as:

$$
E_{e x t}=E_{s c a}+E_{a b s}
$$

For single metal nanoparticle, extinction coefficient is derived by Mie theory and can be expressed as $[6,7]$

$$
E(\lambda)=\frac{24 \pi N_{A} a^{2} \varepsilon_{m}^{3 / 2}}{\lambda \ln (10)} \frac{\varepsilon_{i}}{\left(\varepsilon_{r}+\chi \varepsilon_{m}\right)^{2}+\varepsilon_{i}^{2}},
$$

where $a$ is the radius of the spherical nanoparticle, $N_{A}$ is the areal density of metal nanoparticles, $\lambda$ is the wavelength of incident light ranging from $100-800 \mathrm{~nm}$ and $\chi$ is the aspect ratio of nanoparticle. For spherical shape nanoparticles $\chi=2$. Dielectric constant for the environment of the nanoparticles is given by $\varepsilon_{m}$. The dielectric constant for silver nanoparticle can be obtained from Drude model [8].

\subsection{MAXWELL-GARNETT THEORY}

Maxwell-Garnett theory is used to derive the effective dielectric constant of two materials [9]. Here, we have taken silver nanoparticles with dielectric constant $\varepsilon_{1}$ and the 2D layer of graphene with dielectric constant $\varepsilon_{2}$. According to the Maxwell-Garnett theory, the effective dielectric constant can be written as:

$$
\varepsilon_{e}=\left[f \sqrt{\frac{1}{\varepsilon_{1}}}+(1-f) \sqrt{\frac{1}{\varepsilon_{2}}}\right]^{-\frac{1}{2}} .
$$

Here $f$ defines the fraction of volume of silver nanoparticles in total volume.

Using $\varepsilon_{1}, \varepsilon_{2}$ and $f$ values in Eq.(3.1), we can get the effective dielectric constant. The dielectric constant of Ag NPs

$$
\begin{gathered}
\varepsilon_{1}=A+j B, \\
A=1-\left(\lambda^{2} \lambda_{C}^{2} / \lambda_{p}^{2}\left(\lambda_{C}^{2}+\lambda^{2}\right)\right),
\end{gathered}
$$

$$
B=\lambda^{3} \lambda_{c} / \lambda_{p}^{2}\left(\lambda_{C}^{2}+\lambda^{2}\right) .
$$

The dielectric constant for graphene

$$
\begin{gathered}
\varepsilon_{2}=U+j V, \\
U=\left(9-\frac{\lambda^{2} T^{2}}{9}\right), \\
V=2 T \lambda .
\end{gathered}
$$

Here, $T=5446 \mathrm{~nm}^{-1}$.

By putting these values in Eq. (3.1) and solving, we get the expression for effective dielectric constant containing both real and imaginary parts, which is expressed below

$$
\varepsilon_{e_{f f}}=\left(\frac{E}{E^{2}+F^{2}}\right)+i\left(\frac{-F}{E^{2}+F^{2}}\right)
$$

where

$$
\begin{gathered}
E=f^{2}\left(\frac{A}{A^{2}+B^{2}}\right)+(1-f)^{2}\left(\frac{U}{U^{2}+V^{2}}\right)+ \\
+\frac{2 f(1-f)}{\sqrt{(A U-B V)^{2}+(A V+B U)^{2}}} \cdot H_{R}, \\
F=f^{2}\left(\frac{-B}{A^{2}+B^{2}}\right)+(1-f)^{2}\left(\frac{-V}{U^{2}+V^{2}}\right)+ \\
\frac{2 f(1-f)}{\sqrt{(A U-B V)^{2}+(A V+B U)^{2}}} \cdot H_{I}
\end{gathered}
$$

and

$$
\begin{gathered}
H_{R}=\sqrt{\frac{(A U-B V) \pm \sqrt{(A U-B V)^{2}+(A V+B U)^{2}}}{2}}, \\
\times \sqrt{\frac{H_{I}=-\left(\frac{A V+B U}{\sqrt{2}}\right) \times}{(A U-B V) \pm \sqrt{(A U-B V)^{2}+(A V+B U)^{2}}}} .
\end{gathered}
$$

These real and imaginary parts of the effective dielectric constants are used in the extinction coefficient expression to see the effect of graphene coating on Ag NPs.

\section{RESULTS AND DISCUSSION}

To see the variation of extinction coefficient with the wavelength of light we have plotted Eq. (2) with the wavelength for two different surrounding media.

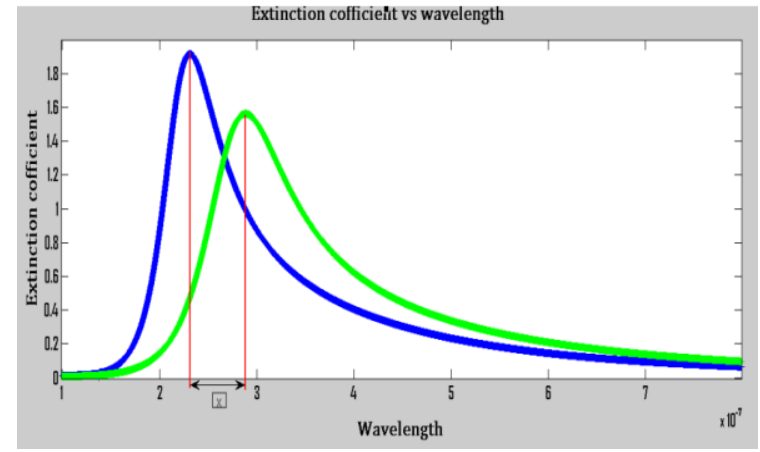

Fig. 2.1 - Extinction coefficient versus wavelength plot for two refractive indices (1) $n=1.333$ (2) $n=1.35$

It can be seen from these curves that the extinction coefficient shows a maximum for a particular value of wavelength. This wavelength is termed as the resonance wavelength and it corresponds to a point where incident wavelength excites the localized surface plasmons. 


\subsection{Effect of Changing Shape of Nanoparticles}

The shape of the nanoparticles affects the absorption band and the resonance wavelength. From the data available in the literature and from our simulation, it is observed that resonance wavelength shifts towards red when shape of the nanoparticles modified from spherical to triangular [10]. Extinction peak is maximum for triangular shaped nanoparticles. These triangular shaped nanoparticles can be used with several modifications like sharpness and roughness of edges and corners, coating of different materials for further research [9].

\subsection{Effect of Changing the Size of Nanoparticles}

From Eq. (2), it can be seen that the extinction coefficient has a dependency on the radius of the nanoparticles. As the size of the nanoparticle is increased from 5 to $15 \mathrm{~nm}$, a sharp increase in the extinction can be observed.

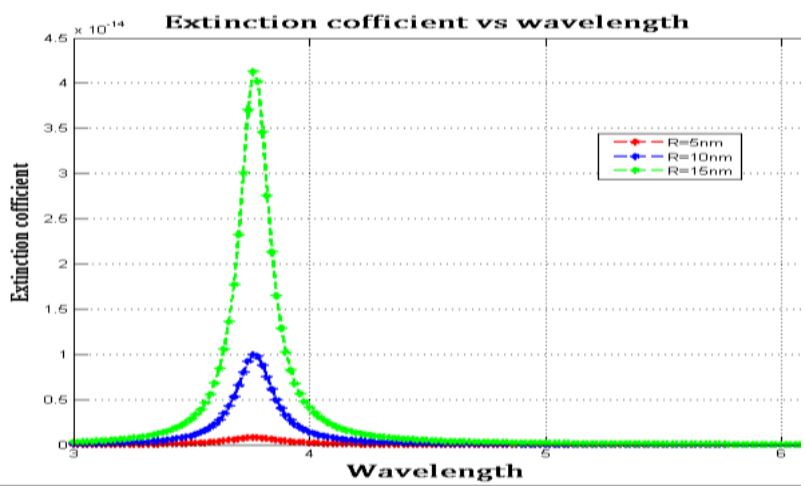

Fig. 2.2 - Extinction coefficient versus wavelength plot for three different sizes of nanoparticles: (i) $5 \mathrm{~nm}$, (ii) $10 \mathrm{~nm}$ and (iii) $15 \mathrm{~nm}$ for the wavelength range $300-600 \mathrm{~nm}$

\subsection{Effect of Changing the Dielectric Constant of the Surrounding Medium}

As the refractive index of the surrounding medium is increased, the extinction peak slightly decreases but a red shift can be observed. This is the essence of the bio sensing. A slight change in the refractive index of the surrounding media can be calibrated in terms of the shift in the resonance wavelength. The greater the shift in the resonant wavelength, the better the sensor will be.

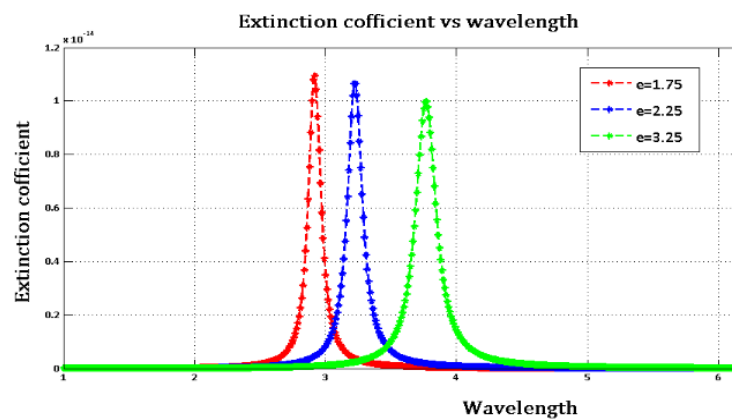

Fig. 2.3 - Extinction coefficient versus wavelength plot for three different dielectric constants of surrounding media of nanoparticles: (i) $e=1.75$, (ii) 2.25 , (iii) 3.25

\section{EFFECT OF GRAPHENE COATING ON SILVER NANOPARTICLES}

Since graphene has been proved to be a better candidate for bio sensing applications, owing to its unique properties such as large surface to volume ratio, that lead to better adsorption of bio molecules on its surface we propose here the coating of graphene layer on to the surface of the nanoparticles. In order to observe the effect of using graphene coating on silver nanoparticles, we have used the effective dielectric constant as derived in Eq. (4) and simulated with MATLAB using the $f$ values: (i) 0.4 , (ii) 0.6 , (iii) 0.8 .

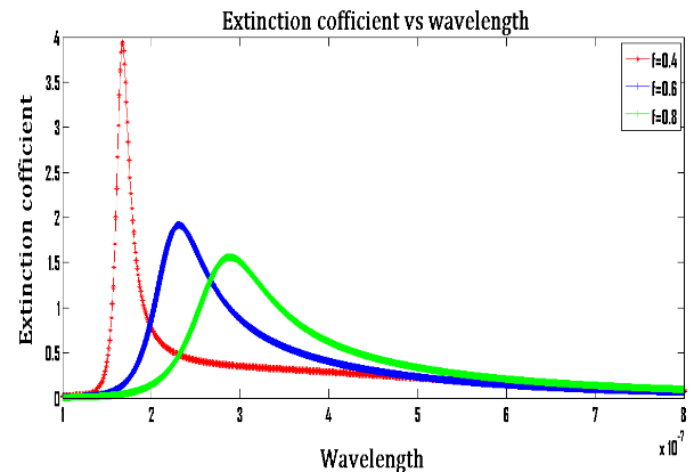

Fig. 3.1 - Extinction coefficient versus wavelength plot for three different fraction values: (i) 0.4 , (ii) 0.6 , (iii) 0.8

As the fraction of volume of silver nanoparticles is increased the extinction peak decreases but a significant shift in resonance wavelength towards red can be observed. This proves that graphene coating can increase the sensitivity of the proposed sensor.

\section{NORMALIZED EVANESCENT EXTINCTION COEFFICIENT}

To realize this mechanism on to the core of the optical fiber we assume that a multimode optical fiber with the bare core at the middle is decorated with the graphene coated silver nanoparticles. A polychromatic light is launched from one end of the optical fiber and the transmitted power is received from the other end. We further calculated the effective absorption coefficient which can be represented as:

$$
A_{\mathrm{eff}}(\lambda)=\left(\frac{\int_{0}^{\pi / 2} A(\theta, \lambda) \frac{n_{1}^{2} \sin \theta \cos \theta}{\left(1-n_{1}^{2} \cos ^{2} \theta\right)^{2}} \mathrm{~d} \theta}{\int_{0}^{\pi / 2} \frac{n_{1}^{2} \sin \theta \cos \theta}{\left(1-n_{1}^{2} \cos ^{2} \theta\right)^{2}} \mathrm{~d} \theta}\right) .
$$

This is the effective evanescent extinction coefficient for single nanoparticle interacting with all the rays launched in to the optical fiber.

Here, $n_{1}$ is defined as the refractive index of the fiber core, $n_{2}$ is the refractive index of the silver nanoparticles and $\theta$ is the critical angle and given by

$$
\theta=\sin ^{-1}\left(\frac{n_{2}}{n_{1}}\right) \text {. }
$$


In order to see the effect on extinction coefficient and resonance wavelength by depositing this combination of nanoparticles and 2D layer on optical fiber, we have plotted the effective absorption coefficient as shown in Fig. 3.2.

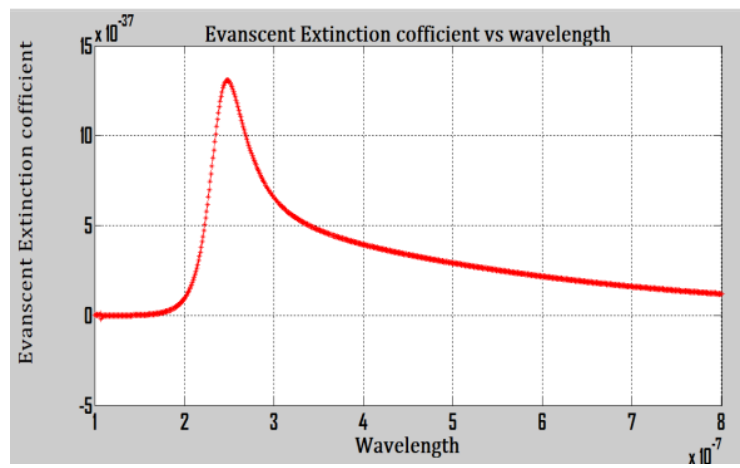

Fig. 3.2 - Effective evanescent extinction coefficient versus wavelength

\section{REFERENCES}

1. B. Liedberg, C. Nylander, I. Lunström, Sensor. Actuat. 4, 299 (1983).

2. B.E. Hutter, J.H. Fendler, Adv. Mater. 16, 1685 (2004).

3. S.K. Srivastava, R.K. Verma, B.D. Gupta, Appl. Opt. 48, 3796 (2009).

4. J. Li, Q. Wu, J. Wu, Synthesis of Nanoparticles via Solvothermal and Hydrothermal Methods Instruments Used in Hydrothermal/Solvothermal Processes, in Handbook of Nanoparticles (Springer International Publishing: Switzerland: 2015).

\section{CONCLUSIONS}

From the theoretical work and analysis, we conclude that the resonance wavelength and extinction coefficient of silver nanoparticles are extremely sensitive to the shape and size of the nanoparticles. Further, different shaped and size of the nanoparticles, such as triangular shaped NPs can be used to interplay with the extinction coefficient. On increasing the surrounding medium refractive index, resonance wavelength shifts towards red. Coating of $2 \mathrm{D}$ material (graphene) has been used to enhance the effects further. These are the preliminary results. Further detailed simulations and experimental work is in the process to calibrate/improve the sensitivity and detection accuracy.

\section{ACKNOWLEDGEMENTS}

This work is partially supported by the DST SERB Core Research Grant CRG/2020/005593.

5. C. Devi, R. Singhal, K. Silva et al., Nanotechnology 31, 235709 (2020).

6. H. Raether, Surface Plasmons on Smooth and Rought Surfaces and on Gratings (New York: Springer-Verlag: 1986)

7. S. Link, M.A. El-sayed, J. Phys. Chem B 103, 4212 (1999).

8. P. Mulvaney, Langmuir 12, 788 (1996).

9. L. Gao, J.Z. Gu, J. Phys. D. Appl. Phys. 35, 267 (2002).

10. H. Song, H. Zhang, Z. Sun, Z. Ren, X. Yang, Q. Wang, AIP Adv. 9, 085307 (2019).

\title{
Моделювання локалізованого поверхневого плазмонного резонансу наночастинок срібла із графеновим покриттям з використанням теорії Максвелла-Гарнета
}

\author{
Kavita, R.K. Verma \\ Department of Physics, Central University of Rajasthan, NH-8 Bandarsindri, Ajmer 305817, \\ Rajasthan, India
}

\begin{abstract}
Поверхневий плазмонний резонанс $(\mathrm{SPR}) €$ важливою технікою для різних оптичних волоконних датчиків, біомедичних додатків, візуалізації та численних оптичних приладів. Поверхневі плазмони - це поперечні магнітно-поляризовані поверхневі хвилі, що утворюються внаслідок збудження поверхневих електронів на межі поділу металу та діелектрика. Збудження поверхневих плазмонів в наночастинках металів демонструе сильну смугу поглинання для UV-Vis області, якої немае в спектрі об'емного шару металів. Такі плазмони називаються локалізованими поверхневими плазмонами (LSPs). LSPs - це колективні коливання вільної електронної хмари в наночастинках металів, які призводять до сильної смуги поглинання. Коли довжина хвилі падаючого світла стає резонансною з довжиною хвилі осцилюючих вільних електронів, явище називають локалізованим поверхневим плазмонним резонансом (LSPR). У роботі ми виконали моделювання за допомогою MATLAB, щоб отримати варіацію перетину екстинкції (що дає значення коефіцієнта поглинання) із довжиною хвилі падаючого світла для покритих графеном наночастинок срібла. Для того, щоб отримати есрективну діелектричну проникність запропонованої структури, аналітично використано теорію Максвелла-Гарнета.
\end{abstract}

Ключові слова: SPR, LSPR, Наночастинка, Датчик, Графен. 